\title{
Cannibalism: Do risks of fighting and reprisal reduce predatory rates?
}

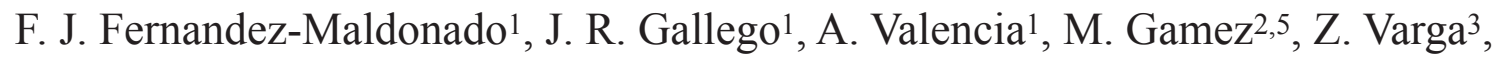 \\ J. Garay ${ }^{4}$ and T. Cabello ${ }^{1}$
}

\author{
${ }^{1}$ Department of Biology and Geology, University of Almeria, Ctra. Sacramento s/n, ES 04120 Almeria, Spain \\ 2 Department of Mathematic, University of Almeria, Ctra. Sacramento s/n, ES 04120 Almeria, Spain \\ 3 Institute of Mathematics and Informatics, Szent Istvan University, H-2103 Gödöllö, Hungary \\ ${ }_{4}$ Department of Plant Systematics, Ecology and Theoretical Biology, L. Eötvös University, Pázmány P. s. 1/c., \\ Budapest, H-1117 Hungary \\ 5 Corresponding author,e-mail: mgamez@ual.es
}

Keywords: Functional response, Heterospecific and conspecific prey, Insect, Nabis pseudoferus, Predatory behaviour, Preypredator relationship, Spodoptera exigua.

\begin{abstract}
Cannibalism is a common phenomenon among insects. It has raised considerable interest both from a theoretical perspective and because of its importance in population dynamics in natural ecosystems. It could also play an important role from an applied perspective, especially when using predatory species in biological control programmes. The present paper aims to study the cannibalistic behaviour of Nabis pseudoferus Remane and the functional response of adult females. In a non-choice experiment, adult females showed clear acceptance of immature conspecifics as prey, with relatively high mortality values $(51.89 \pm 2.69 \%)$. These values were lower than those occurring for heterospecific prey, Spodoptera exigua Hübner, under the same conditions $(80.00 \pm 2.82 \%)$. However, the main result was that the rate of predation on heterospecific prey was reduced to $59.09 \pm 7.08 \%$ in the presence of conspecific prey. The prey-capture behaviour of adult females differed when they hunted conspecific versus heterospecific prey. This was shown in the average handling time, which was $23.3 \pm 3.3$ min in the first case (conspecific) versus $16.6 \pm 2.5 \mathrm{~min}$ in the second (heterospecific). Furthermore, the values increased in the former case and declined in the latter according to the order in which the prey were captured. The difference in handling time was not significant when adjusting the adult female functional response to conspecific nymphs. We argue that these results likely indicate risk aversion and a fear of reprisal among conspecifics.
\end{abstract}

\section{Introduction}

Cannibalism, defined as intraspecific predation, occurs frequently in nature. It has been observed in more than 1,300 species, including protozoa, turbellaria, rotifers, snails, copepods, centipedes, spider mites, scorpions, spiders, insects, fishes, frogs, birds and mammals (Fox 1975, Polis 1981, Joyner and Gould 1987). In insects, cannibalism is a common behaviour that has been well-documented in many orders, including Odonata, Orthoptera, Thysanoptera, Hemiptera, Trichoptera, Lepidoptera, Diptera, Neuroptera, Coleoptera and Hymenoptera (Capinera, 2010). It occurs in both terrestrial and aquatic habitats and among carnivorous and herbivorous species (Joyner and Gould 1987). Cannibalism involves predation by adults and other mobile life stages (larvae or nymphs) on less developed or weaker stages as well as on non-mobile stages (e.g., eggs) (Joyner and Gould 1987).

There are many types of cannibalism. These can be defined according to the damage caused to the cannibalised individual: destructive (when the prey undergoes injuries or death) or non-destructive cannibalism (which does not cause serious damage to the prey individual) (Joyner and Gould 1987). Cannibalism can also be classified in relation to the degree of genetic relatedness between cannibal and prey
(Santana et al. 2012). This is important since the potential loss of inclusive fitness will depend clearly on the degree of relatedness (Dixon 2000). Thus, cannibalism can also be subdivided into categories, such as heterocannibalism (the cannibal and prey are unrelated), filial cannibalism (parents prey upon their own offspring), or sibling cannibalism (siblings prey upon each other) (Dixon 2000).

The occurrence of cannibalism in insects may be due to different causes, as recently reviewed by Santana et al. (2012), such as genetic characteristics, food availability and quality, population density, availability of victims, etc. Cannibalism is often increased by overcrowded conditions at high population densities (Polis 1981) and influenced by other stressors, such as the lack of food (Joyner and Gould 1987). However, Santana et al. (2012) noted that cannibalism at high population densities has been wrongly attributed to the lack of food since there are examples of cannibalism at high densities even when food is sufficient or plentiful.

When food is sufficient, there are two possible ways to explain the cannibalism-density association (Polis 1981). First, changes in cannibalism rates may co-vary with conspecific density for the same reasons that predators show different responses depending on the density of heterospecific prey. Second, many species do not tolerate the presence of 
conspecifics in their own territory. Thus, overpopulation may increase the frequency of conspecific encounters and hence increase cannibalism in high-density populations.

The damsel bug Nabis pseudoferus Remane (Hemiptera: Nabidae) is a generalist predator rather than being omnivorous (e.g., Fagan 1997). Although most studies involving Nabidae species use feeding trials with plants (Braman 2000), they are unable to complete their developmental cycle in the absence of prey. The feeding trials indicate that Nabidae species feed on plants to obtain water (Hagen et al. 1999) and that they seem to do little or no harm to plants, while such behaviour can help the predators survive during periods of food scarcity (Braman 2000). N. pseudoferus has a wide range of arthropod prey (predominantly insects and mites) (Puchkov 1980, Cabello 1988, Ulusoy and Ulgenturk 2003). It is worth mentioning that $N$. pseudoferus is often used as a biological control agent against lepidopteran pests in greenhouse crops (Vila and Cabello 2014).

Adults and nymphs of $N$. pseudoferus show a type II functional response to the larvae of beet armyworm or small mottled willow moth, Spodoptera exigua Hübner (FernandezMaldonado unpublished data). In general, other Nabis species also present type II responses in their nymph and adult stages. This is the case with Nabis americoferus Carayon (Propp, 1982), Nabis kinbergii Reuter (Siddique et al. 1987), Nabis capsiformis Germar (Fathipour and Jafari 2003), and other unidentified Nabis species (Stasek 2009).

Cannibalism in N. pseudoferus has also not been documented. In fact, there have only been a few studies on cannibalism in species of this genus, except for the American species Nabis alternatus Parshley and Nabis roseipennis Reuter (Perkins and Watson 1972).

Current biological control systems are quite complex, especially in greenhouse crops, where different species of natural enemies (predators, parasitoids and entomopathogens) are often used at the same time within the same crop cycle to control different phytophagous species (Vila and Cabello 2014). It has become increasingly important, sometimes even crucial, to understand the ecological relationships among them (e.g., Cabello et al. 2015). Regarding ecological relationships, little thought has been given to the effects of cannibalism, although they could erode the effectiveness of biological control. Indeed, high densities of natural enemies are often used, especially in augmentative biological control programmes (e.g., Cabello et al. 2012), even as a preemptive measure in the absence of the phytophagous target pest species.

Interestingly, the effect of cannibalism has received little or no attention in biological pest control programmes. On one hand, the effects of cannibalism may suppress production in mass breeding efforts (Clercq et al. 2014). On the other hand, as mentioned previously, the release rates of natural enemies can lead to high densities when prey pest levels are very low or before the prey infests the crop (e.g., Vila and Cabello 2014). All of this suggests that cannibalism may influence the efficacy of biological control methods (e.g., Mills 1982).
The present paper aims to study the importance of cannibalism in N. pseudoferus, a predator often used in biological pest control programmes. The study was carried out under laboratory conditions to evaluate the preference of adult females for heterospecific versus conspecific prey by means of choice and non-choice trials and to reveal the functional response of adult females, as cannibalism may be dependent on conspecific density.

\section{Materials and methods}

\subsection{Biological material and experimental conditions}

A colony of $N$. pseudoferus was established from wild populations at different locations (Granada and Almeria, Spain) and reared under laboratory conditions. We used plastic containers (12 1) equipped with a cardboard panel to act as a shelter material, bean pods as a substrate for oviposition and a water source, and Mediterranean flour moth (Ephestia kuehniella Zeller (Lepidoptera: Pyralidae)) eggs as prey. The eggs were supplied frozen (Ephescontrol ${ }^{\circledR}$, Agrobio S.L., La Mojonera, Almeria, Spain) and kept at $-40^{\circ} \mathrm{C}$ until use. The $N$. pseudoferus specimens used in the trials were kept in the laboratory for only two generations before performing the trials. The $S$. exigua larvae used as prey were provided as eggs by the company Entomotech S.L. (Almeria, Spain). After hatching, the larvae were reared on an artificial diet following the methodology described by Cabello et al. (1984) up to the second larval stage. The conditions for rearing and conducting the two tests were $25 \pm 1{ }^{\circ} \mathrm{C}, 60-80 \% \mathrm{HR}$ and a photoperiod of 16:8 light:darkness ratio.

The laboratory arena method was used in all trials. Despite the fact that this method may underestimate the daily consumption of prey in relation to the use of field cages, it is still considered appropriate to use this method to estimate such values (Latham and Mills 2009). The arenas were Petri dishes $(\varnothing=9 \mathrm{~cm}$, height $=1.5 \mathrm{~cm})$ sealed with Parafilm $\subset$ to prevent the escape of $S$. exigua larvae.

\subsection{Prey preference trial}

Experimental design and methodology. The preference trial was conducted with adult females and second-instar nymphs of the predator ( $N$. pseudoferus), as second-instar nymphs have proven to be most susceptible to cannibalism by adult females (Fernandez-Maldonado unpublished data). The test design was completely random. The experimental treatment consisted of three levels: non-choice with heterospecific prey (second-instar larvae of $S$. exigua), non-choice with conspecific prey (second-instar nymphs of N. pseudoferus) and choice (heterospecific larvae and conspecific nymphs together). Twenty-four replicates were carried out for each treatment.

The trial methodology was adapted from Cabello et al. (2015). N. pseudoferus adult mated females were used less than one week after final nymphal ecdysis. They were individually isolated in Petri dishes and subjected to a starving 
period of $24 \mathrm{~h}$ prior to testing. They were only given a piece of sponge moistened with distilled water.

Twelve specimens of a single species (second-instar larvae of $S$. exigua as heterospecific prey or second-instar nymphs as conspecific prey) were introduced in the nonchoice treatments, whereas 6 specimens of both the heterospecific and conspecific prey species were introduced in the choice treatment. Each adult female predator was left to prey on them for a period of $4 \mathrm{~h}$.

Recorded data. Two types of data were recorded: a) the number of prey killed was annotated at the end of the trial $(4 \mathrm{~h})$ for each treatment and replicate, and b) the prey-capture behaviour of adult females was recorded. Since direct human observation may interfere with the predation behaviour of Nabis species (Wade et al. (2005), we photographed the trial arena every 10 seconds using an Eos 550D $\left(\mathrm{Canon}^{\circledR}\right)$ digital camera, EFS 18-55 lens with macro function $\left(\mathrm{Canon}^{\circledR}\right)$, connected with a cable to a computer. The software used was Communication Software for the Camera EOS Utility, version 2.14 (Canon 2014). Due to the type of lens and pixel resolution, images of only six arenas could be captured simultaneously, and it thus took 12 days to complete all treatments and replicates. Different treatments and replicates were randomly assigned to photo shoots. For the above reasons, these replicates are actually pseudoreplicates and were treated as such in the statistical analysis, as indicated below.

Photographs were set in time-lapse using the Image Processing and Analysis in Java (ImageJ) software, version 1.49 (Schneider et al. 2012), which recorded the behaviour, the duration of a predation event, the identity of the killed prey, and the sequence of predation events.

The time needed for predation events was quantified as the handling time $\left(T_{h}\right)$ (Holling 1959). This comprises the time spent in quelling, killing and eating prey as well as the time spent cleaning the predator's body and appendages and the resting time. The time spent exclusively in searching for prey $\left(T_{s}\right)$ was also recorded. The sum of the two values equals the total available time $(T), 4 \mathrm{~h}$ in this case.

Statistical analysis. Since the trials had to be performed on different days, the treatment replicates do not represent real replicates in a strictly randomized design. This is common in insect behavioural studies, for example, when using olfactometers (of which only one or very few are available), as indicated by Ramirez et al. (2000). Under these circumstances, traditional statistical analysis of variance (ANOVA) and general linear models (GLMs) cannot be applied, but generalized linear models (GZLMs) (Ricard 2008) can be applied. Additionally, the statistical analyses assessed the effects of 'treatments'. The variable 'day' was included as an explanatory variable to avoid pseudoreplication. In the case of studies of organism preference, when there is a single count variable (with a Poisson distribution), generalized linear models (GZLMs) are the most powerful statistical methods from a statistical point of view (Mangeaud and Videla 2005).

Therefore, data corresponding to the number of prey killed were analysed using the GENLIN procedure (GZLMs) In the analysis of these data, a single factor was used at three levels: non-choice with heterospecific prey, non-choice with conspecific prey and choice between both. The analysis used a Poisson distribution and log-linear link function. The analysis of the measured times, i.e., handling time $\left(T_{h}\right)$ and searching time $\left(T_{s}\right)$, considered two factors: Factor 1, Factor 2 and Factor $1 \times$ Factor 2 (Factor 1 as before and Factor 2 as the handling time of prey by the predator or the searching time). All analyses were carried out using the statistical program SPSS, version 21 (IBM 2012).

Additionally, in the choice treatment, adult predators' preferences towards different offered prey was studied using the Manly preference index ( $\mu$ ) (Manly et al. 1972). As established by Cock (1978), the Manly index is the only method that takes into account the reduction in prey density that occurs during the course of the trial. This has been corroborated in the review by Sherratt and Harvey (1993). The index is given bz the following equation:

$$
\mu=\frac{\frac{r_{i}}{N_{i}}}{\frac{r_{i}}{N_{i}}+\frac{r_{j}}{N_{j}}}
$$

where $r_{i}=$ number of prey $i$ consumed, $r_{j}=$ number of prey $j$ consumed, $N_{i}=$ number of prey $i$ offered, and $N_{j}=$ number of prey $j$ offered.

\subsection{Functional response}

Experimental design and methodology. The trial to establish the type of functional response was conducted with female adults as predators and dead second-instar nymphs as prey. The nymphs were previously collected from laboratory cultures and stored at $-40{ }^{\circ} \mathrm{C}$ until use. By using dead prey items, we aimed to eliminate the "fight" factor from the handling times $\left(T_{h}\right)$. The experimental design was completely random, with a single treatment (conspecific prey density) at seven levels. The number of replicates per treatment was 10. All treatments and replicates were carried out simultaneously in a single trial.

All N. pseudoferus adult females were the same age and had been handled the same way as in trial 1 . They were placed in Petri dishes for $24 \mathrm{~h}$ without food and with only a water supply. After that time, dead conspecific second-instar nymphs were introduced to the dishes. The densities of dead prey used were $1,3,6,9,12,15$ or 18 . After $24 \mathrm{~h}$, adult females were removed, and the number of consumed nymphs was evaluated (based on the remaining exoskeletons).

Statistical analysis. Two types of analysis were conducted using data from the consumed conspecific prey. First, a logistic regression was performed between the proportion of consumed prey and the density of offered prey according to the polynomial function used by Juliano (2001) by means of the following equation: 
$\frac{N_{e}}{N_{0}}=\frac{E X P\left(P_{0}+P_{1} \cdot N_{0}+P_{2} \cdot N_{0}^{2}+P_{3} \cdot N_{0}^{3}\right.}{1+E X P\left(P_{0}+P_{1} \cdot N_{0}+P_{2} \cdot N_{o}^{2}+P_{3} \cdot N_{0}^{3}\right)}$

where $N_{e}=$ number of consumed prey; $N_{0}=$ initial value of available prey; and $P_{0}, P_{1}, P_{2}$ and $P_{3}$ stand for cut-off, linear, quadratic and cubic coefficients, respectively, estimated according to the maximum likelihood method. The parameters $P_{0^{-}} P_{3}$ were obtained by logistic regression.

The logistic regression procedure and the method of maximum likelihood estimation were carried out using the statistical software package Statgraphic Centurion XVI, version 16.1.18 (Statgraphics 2010).

Second, the data were adjusted to the three functional response types according to equations suggested by Cabello et al. (2007), as follows:

- Type I functional response:

$N_{a}=N\left[1-\exp \left(-a^{\prime} \cdot T \cdot P\right]\right.$

where $N_{a}=$ number of consumed prey, $N=$ number of available prey, $a^{\prime}=$ instantaneous search rate (1/day), $T=$ total time available for searching (d), and $P=$ number of predators. In this study, $P=1$ (predator) and $T=1$ (day).

- Type II functional response:

$N_{a}=N\left\{1-\exp \left[a^{\prime} \cdot P\left(T-T_{h} \cdot \frac{N_{a}}{P}\right)\right]\right\}$

where $T_{h}$ is the handling time (days), and the rest are as before. Similarly, $P=1$ and $T=1$ (day).

- Type III functional response:

$$
N_{a}=N\left\{1-\exp \left[-\frac{\alpha \cdot N \cdot P}{1+T_{h}(\exp (-\alpha)-1) \cdot N} \cdot\left(T-T_{h} \cdot \frac{N_{a}}{P}\right)\right]\right\}
$$

where $\alpha$ measures the predation potential (value between 0 and 1), and the remaining variables are similar to those in previous responses; also, $P=1$ (predator) and $T=1$ (day).
Table 1. Mean $( \pm \mathrm{SE})$ number of prey killed by N. pseudoferus adult females when exposed to $S$. exigua second-instar larvae versus conspecific second-instar nymphs in non-choice and choice tests (means with the same letter are not significantly different from each other at $P=0.05$ ).

\begin{tabular}{lcc}
\hline \multirow{2}{*}{ Treatment } & \multicolumn{2}{c}{ Number of dead prey } \\
\cline { 2 - 3 } & Mean & SE \\
\hline Non-choice: heterospecific prey & $8.71 \mathrm{a}$ & 1.18 \\
Non-choice: conspecific prey & $6.23 \mathrm{~b}$ & 1.05 \\
Choice: both & $5.41 \mathrm{~b}$ & 0.97 \\
\hline
\end{tabular}

The adjustments to the previous equations were completed by non-linear regression using the statistical software package Tablecurve 2D, version 5.0 (Jandel Scientific, 1994).

To select the best adjustment type, the corrected Akaike information criterion $\left(A I C_{c}\right)$ was used, as it has been shown to be more accurate for statistically comparing models than the regression coefficient $\left(R^{2}\right)$ (Motulsky and Christopoulus 2003). However, $R^{2}$ was used to establish the goodness of fit of the non-linear regression adjustments.

\section{Results}

\subsection{Prey preference trial}

Table 1 shows the mean number of specimens killed by $N$. pseudoferus female adults in the prey preference trial according to prey species and the non-choice and choice treatments. Figure 1 shows such values in percentages.

The statistical analysis performed by GZLMs indicated that, in the omnibus test, when the adjusted model was compared with the model including only the intercept, the modelexplained variance exceeded the unexplained variance (likelihood ratio $\left.\chi^{2}=19.609, d f=2, P<0.0001\right)$. Likewise, in the model-effect test, a highly significant effect was found for the type of prey (only natural prey, only conspecific or both) available to predatory females (Wald $\chi^{2}=19.749, d f=2, P$ $<0.0001)$.

In the choice treatment, in the presence of conspecific and heterospecific prey items, only a single nymph was observed to kill and eat a $S$. exigua larva, a fact not considered in the
Figure 1. Mean percentages $( \pm \mathrm{SE})$ of dead prey in a preference trial using $N$. pseudoferus adult females exposed to $S$. exigua secondinstar larvae versus conspecific second-instar nymphs in non-election and election options.

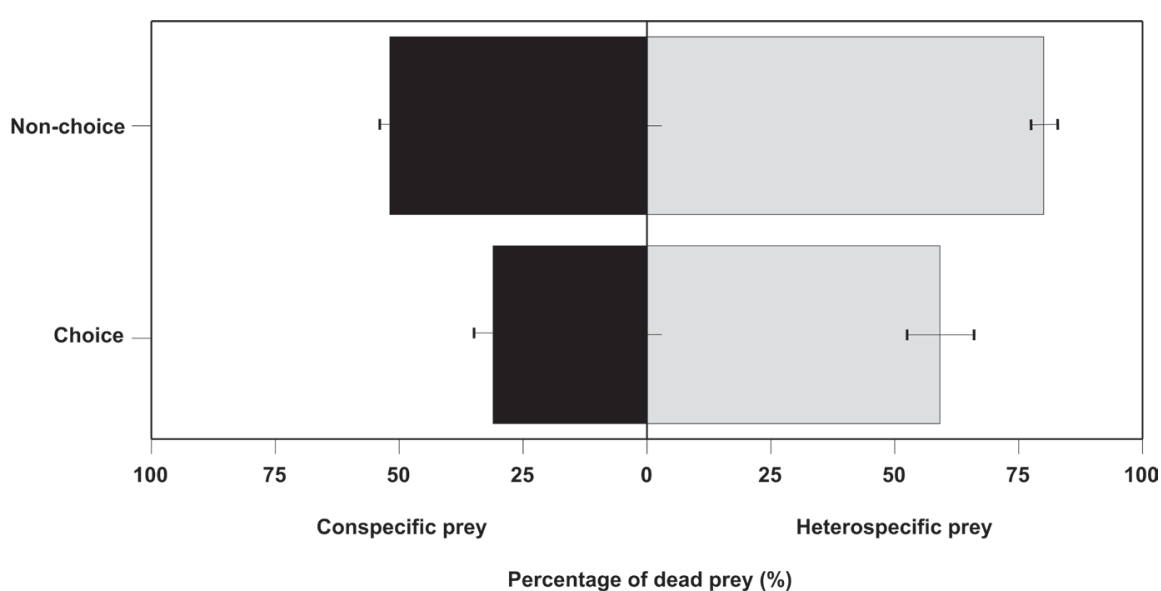




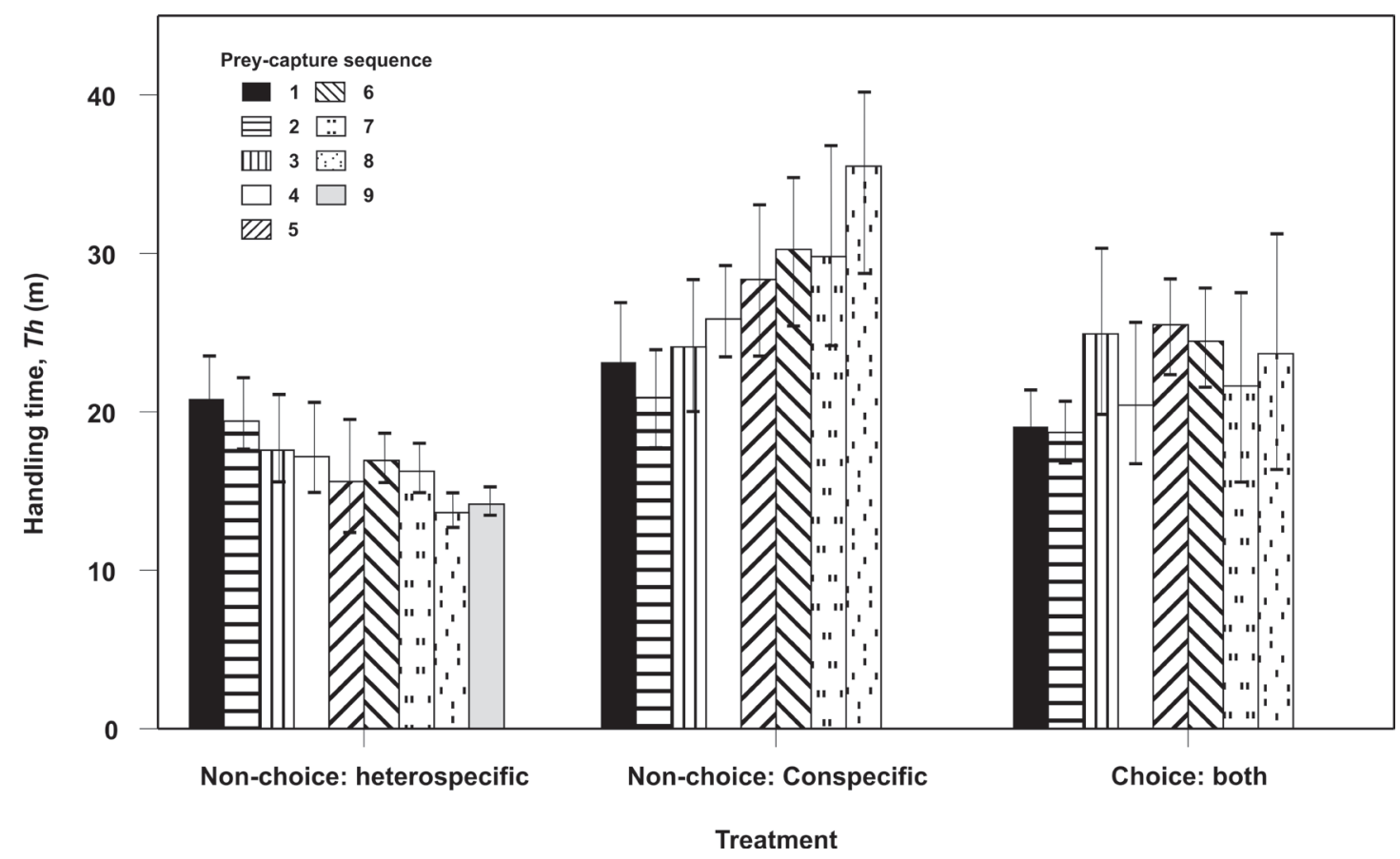

Figure 2. Mean handling times ( $\pm \mathrm{SE})$ of $N$. pseudoferus adult females in the prey preference trials (heterospecific or conspecific prey: S. exigua second-instar larvae or N. pseudoferus second-instar nymphs).

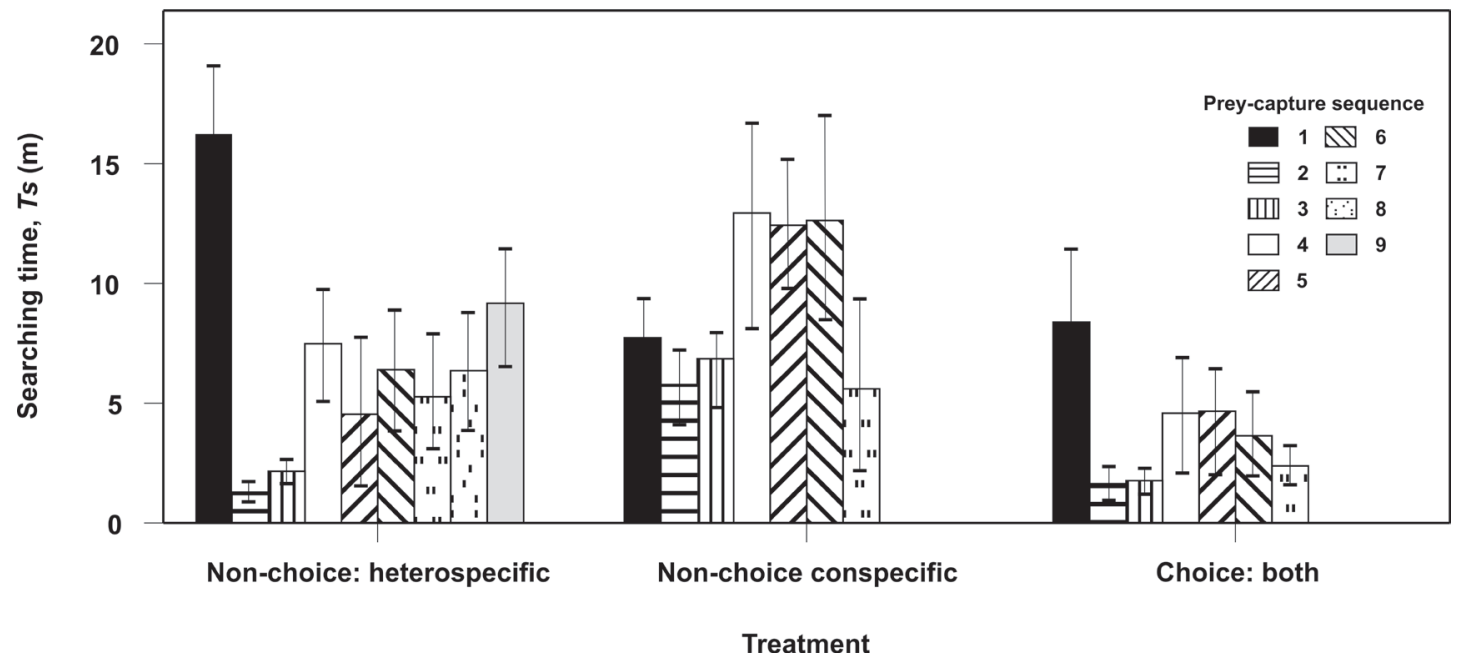

Figure 3. Mean searching times $( \pm \mathrm{SE})$ of $N$. pseudoferus adult females in the prey preference trials (heterospecific or conspecific prey: S. exigua second-instar larvae or N. pseudoferus second-instar nymphs).

data analysis. Additionally, no second-instar nymph of $N$. pseudoferus was observed to kill a conspecific nymph.

Adult females accepted both S. exigua and their conspecifics as prey (Table 1). However, the number of prey killed by predatory females was significantly higher in the $S$. exigua non-choice treatment than in the other two treatments. The Manly preference index $(\mu)$ supports these results. The value of $\mu$ indicates preference when it exceeds 0.5 , rejection when it is lower than 0.5 and indifference when it is exactly 0.5 . In our trials, predators showed a clear preference for $S$. exigua larvae $\left(\mu_{1}=0.74 \pm 0.06, \mathrm{n}=24\right)$ and rejection of conspecific nymphs $\left(\mu_{2}=0.26 \pm 0.06, \mathrm{n}=24\right)$. On the other hand, the presence of conspecifics (whose body size is similar to that of heterospecific prey) reduced females' predation activity in the non-choice and choice treatments (Fig. 1).

Figures 2-3 show handling times $\left(T_{h}\right)$ for adult females and their actual searching time $\left(T_{s}\right)$. Both values correspond to the sequence of prey captures. The omnibus test also showed high significance in the model-explained variance (likelihood ratio $\left.\chi^{2}=17.901, d f=2, P<0.0001\right)$. Additionally, a highly significant effect was found for the handling time of the prey $\left(T_{h}\right)$ for the experimental treatment (Wald $\chi^{2}=17.901, d f=2$, $P<0.0001$ ) but not for the sequence of prey captures (Wald $\left.\chi^{2}=5.219, d f=11, P=0.920\right)$. 
Table 2. Mean durations $( \pm \mathrm{SE})$ of predatory activity (searching and handling time) in N. pseudoferus adult females when exposed to $S$. exigua second-instar larvae versus conspecific second-instar nymphs in non-choice and choice tests (means with the same letter are not significantly different from each other at $P=0.05$ ).

\begin{tabular}{|c|c|c|c|}
\hline \multirow{2}{*}{ Times } & \multirow{2}{*}{ Treatment } & \multicolumn{2}{|c|}{ Time (m) } \\
\hline & & Mean & SE \\
\hline \multirow[t]{3}{*}{ Handing $\left(T_{h}\right)$} & $\begin{array}{l}\text { Non-choice: heterospe- } \\
\text { cific prey }\end{array}$ & $16.6 \mathrm{a}$ & 2.5 \\
\hline & $\begin{array}{l}\text { Non-choice: conspecific } \\
\text { prey }\end{array}$ & $23.3 \mathrm{~b}$ & 3.3 \\
\hline & Choice: both & $21.9 \mathrm{~b}$ & 3.4 \\
\hline \multirow[t]{3}{*}{ Searching $\left(T_{s}\right)$} & $\begin{array}{l}\text { Non-choice: heterospe- } \\
\text { cific prey }\end{array}$ & $5.3 \mathrm{a}$ & 1.9 \\
\hline & $\begin{array}{l}\text { Non-choice: conspecific } \\
\text { prey }\end{array}$ & $8.4 \mathrm{~b}$ & 2.5 \\
\hline & Choice: both & $3.2 \mathrm{a}$ & 2.6 \\
\hline
\end{tabular}

Table 3. Maximum likelihood estimates from logistic regression of proportion of conspecific prey consumed by N. pseudoferus adult females as a function of initial prey densities.

\begin{tabular}{lccccc}
\hline Parameters & Values & SE & \multicolumn{2}{c}{$\begin{array}{c}\text { Confidence } \\
\text { limits }(95 \%)\end{array}$} & $\begin{array}{c}\text { Predicted } \\
\text { function }\end{array}$ \\
\hline$P_{0}$ (Intercept) & 5.3479 & 1.4103 & 0.8595 & 9.8363 & Type I \\
$P_{1}$ (Lineal) & -1.3926 & 0.4228 & -2.7381 & 0.0470 & \\
\hline
\end{tabular}

Table 4. Parameters and statistical significance for functional response equations for numbers of conspecific nymphs consumed by $N$. pseudoferus adult females.

\begin{tabular}{lllllll}
\hline Functional & \multicolumn{3}{c}{ Parameters } & \multicolumn{4}{c}{ Statistical parameters } \\
\cline { 2 - 7 } response & $a^{\prime}\left(\right.$ day $\left.^{-1}\right)$ & $\square$ & $T_{h}$ (day) & $d f$ & $R^{2}$ & $A I C_{C}$ \\
\hline Type I & 0.6807 & - & - & 5 & 0.9802 & -6.5151 \\
Type II & 1.8654 & - & 0.1105 & 7 & 0.9742 & -5.2716 \\
Type III & - & 0.4281 & 0.1480 & 7 & 0.9493 & -1.9275 \\
\hline
\end{tabular}

Figure 4. Mean $( \pm \mathrm{SE})$ number of conspecific second-instar nymphs consumed by $N$. pseudoferus adult females and values predicted by a type-I functional response model at different density levels.

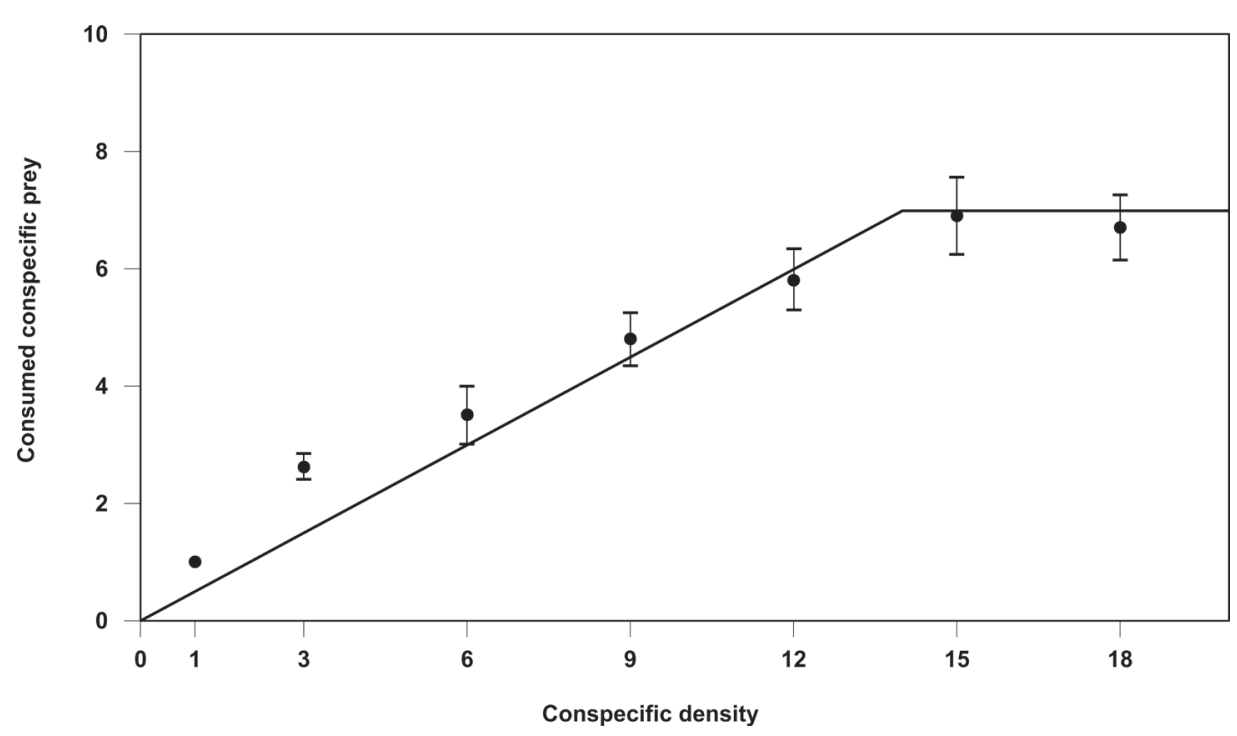

As for the searching time $\left(T_{s}\right)$, the omnibus contrast was also highly significant (likelihood ratio $\chi^{2}=39.352, d f=13$, $P<0.0001)$. Both the treatment and the capture sequence had significant effects on the searching time (Wald $\chi^{2}=15.516$, $d f=2, P<0.0001$ and Wald $\chi^{2}=26.285, d f=11, P=0.006$, respectively).

Likewise, the searching time $\left(T_{s}\right)$ for the first capture of heterospecific prey was high, likely due to the lack of learning among adult females (Fig. 3). In general terms, searching times were erratic and shorter than handling times. Table 2 shows the mean values of both handling and searching times. The average handling time $\left(T_{h}\right)$ was significantly higher in the presence of conspecifics (choice and non-choice treatments). By contrast, the average searching time $\left(T_{s}\right)$ was significantly higher when only conspecifics were present (non-choice treatment).

\subsection{Functional response}

As a prior adjustment, a logistic regression between the proportion of consumed prey and the density of offered prey was performed to estimate the type of functional response. The values obtained are shown in Table 3. According to Juliano (2001), the $P_{1}$ coefficient is not significantly different from zero (it is considered different from zero when the latter is not included in its confidence interval) in type I; the $P_{1}$ coefficient is significantly negative in type II and positive in type III.

This was confirmed by adjusting the data to the three functional response types using the equations presented by Cabello et al. (2007), and then comparing them using the corrected Akaike information criterion $\left(A I C_{c}\right)$. Type I functional response presented the lowest $A I C_{c}$ value (Table 4), and it best represents the behaviour of adult female predators in response to variation in the density of dead conspecifics (Fig. 4). 


\section{Discussion}

Nabis pseudoferus is a generalist predator (Fagan 1997) and shows sit-and-wait behaviour (Schmitz 2007). Hurd (2008) noted that generalist arthropod predators are typically bitrophic (occupying the $3^{\text {rd }}$ and $4^{\text {th }}$ levels simultaneously), as they feed on herbivores and on other predators, the latter involving what is called 'intraguild predation' (IGP). Due to the non-omnivorous nature of $N$. pseudoferus, the absence of prey (both phytophagous and/or other predatory species) involves the need for intraspecific predation or cannibalism, as shown by the results of our study.

Our preference trials showed that $N$. pseudoferus adult females have a clear preference for preying on immature conspecifics, causing relatively high mortality values $(51.89 \pm$ $2.69 \%$ ) (Fig. 1). This cannibalistic behaviour has previously been found in this species (Fernandez-Maldonado unpublished data) and other species of the genus, such as $N$. alternatus (Perkins and Watson 1972), Nabis ferus (L.) and Nabis punctatus A. Costa, (Puchkov 1980). This is consistent with Hurd (2008), who reported that most generalist predatory arthropods are cannibalistic.

However, the cannibalism values found for N. pseudoferus adult females in the non-choice treatments were significantly lower than the values of predation on the heterospecific prey $($ S. exigua) $(80.0 \pm 2.82 \%)$ (Fig. 1). This indicates a lower preference for conspecific than phytophagous prey, a fact that was also confirmed by the preference index $(\mu)$ in the choice treatment. This is a logical result, as previous studies have shown that the density of heterospecific prey reduces cannibalism rates in hemipteran species (e.g., Leon-Beck and Coll 2007, Hamdi et al. 2013) as well as in other animal groups (e.g., Fox 1975).

At first sight, these differences may seem to be caused by the different nutritional values of conspecific versus heterospecific prey. Following this line of reasoning, it has been suggested that some carnivores can balance their diet based on prey composition (Mayntz et al. 2005). However, the reduced rate of cannibalism may signify an anti-cannibalism effect or the energetic costs of fighting with conspecifics, as has been noted in other arthropods (e.g., Riechert 1988, Hack 1997). Polis (1981) indicated that in some species, cannibalism may not be frequent because of the risks of reprisals or reprisal costs. This will be discussed below along with the results of our functional response trials.

The percentage of cannibalism decreased in the presence of heterospecific prey in the choice treatment $(31.06 \pm 4.43 \%)$ compared to the non-choice treatment $(51.89 \pm 2.69 \%)$ (Fig. $1)$. This seems logical and has already been reported in cases where an increase in the density of heterospecific prey reduced the cannibalism rate (e.g., Wagner and Wise 1996, Rudolf 2008).

In contrast, the same phenomenon surprisingly occurred in the case of heterospecific prey; the percentage of specimens killed in the non-choice trial was $80 \%$, which decreased to $59.09 \pm 7.08 \%$ in the choice treatment (Fig. 1). Overall, $N$. pseudoferus females kill significantly fewer prey in the presence of conspecifics, regardless of whether they occur alone or with heterospecifics (Table 1). In some predatory arthropods, the mortality of heterospecific prey is similar in the presence or absence of conspecifics, as is the case with adult female coccinellids (Aleosfoor et al. 2014). In vertebrates, it has also been found that cannibalism rates can be higher than predation rates on heterospecific prey due to their better escape behaviour (Rudolf 2008) or defence (Kishida et al. 2009). Therefore, according to the literature consulted, this is the first case cited in predatory insects, although it has been mentioned in other animal groups as a novelty (Rudolf 2008). The same implies that there is a lower predation rate on heterospecifics in the presence of conspecifics. The reason could be found in the previously mentioned risks of fighting between conspecifics.

Adult females' prey-capturing behaviour was different for conspecific versus heterospecific prey, as reflected in their handling time $\left(T_{h}\right)$ (Fig. 2). In the sequence of prey items, handling times increased for conspecific prey but decreased for heterospecific ones. Overall, the handling time was significantly longer when capturing conspecific prey (Table 2). The increase in conspecific handling time may indicate an aversion to capturing them. This has been noted in some species of spiders regarding toxic prey (Toft and Wise 1999). Likewise, the handling time of prey is important in determining prey profitability and should decrease as prey resistance diminishes (Dong and Polis 1992). This is consistent with the two strategies usually described in the foraging behaviour of predators: active and passive selection. While active selection occurs when predators select prey with high energy content and that require minimal energy to be captured, passive selection should be related to predator-prey encounter rates and capture success (Weber et al. 2010).

The decreased number of heterospecific prey killed in the presence of conspecifics (choice treatment, Table 1 and Fig. 1) may possibly be explained by the longer handling time for conspecific prey (Fig. 2). The time spent handling prey affects the response by decreasing the time available for active searching (Holling 1961).

N. pseudoferus adult females exhibit a type II functional response for $S$. exigua second-instar larvae (FernandezMaldonado unpublished data), similar to other Nabis species (Propp 1982, Siddique and Chapman 1987, Fathipour and Jafari 2003, Stasek 2009). However, N. pseudoferus adult females exhibited a type I functional response in our trials when dead conspecific prey were offered (Fig. 4).

According to nutritional ecology theory, the type of a predator's functional response may vary because predators must adjust their prey capture and consumption rates to the nutritional composition of the prey and other factors (Bressendorff and Toff 2011).

The same effect (a change in the functional response from type II to I) was also observed with an increase in the predation rate for Nesidiocoris tenuis (Reuter) (Hemiptera: Miridae) in IGP with the egg parasitoid Trichogramma achaeae Nagaraja and Nagarkatti (Hymenoptera: Trichogrammatidae) (Cabello et al. 2015) and in interspecific competition between two 
parasitoid species, Chelonus oculator (F.) (Hymenoptera: Braconidae) and Trichogramma brassicae Bezdenko (Cabello et al. 2011).

The type I functional response found for $N$. pseudoferus adult females under the above conditions (Fig. 4) implies a linear increase in the rate of prey consumption until a threshold value of maximal consumption is reached. This type of functional response indicates that the predators have a negligibly small handling time (Jeschke et al. 2004). From a theoretical point of view, when there is no handling time, the total opportunism provides a maximal gain of energy for the predator (Garay and Mori 2010).

Our results also indicate the lack of an apparent adverse effect to the prey due to nutritional properties; rather, cannibalism in this species is likely motivated by risk aversion (associated with conspecific fight) and the energy costs of starvation. Killing a conspecific may reduce the cannibal's own inclusive fitness (Pfennig et al. 1993) while also exposing it to the threat of reprisal from a prey individual having similar predatory skills (Elgar and Crespi 1992).

Furthermore, our results seem to support those of Schenk et al. (2005), who studied the Polistes dominulus (Christ) (Hymenoptera: Vespidae) - Cassida rubiginosa Müller (Coleoptera: Chrysomelidae) system and noted that the functional response depended on the abundance of both prey and predator. Therefore, the system is affected by both direct (e.g., aggression) and indirect mechanisms (depletion of easy-to-find prey). This view can be extended to cannibalism in our present study.

These findings suggest the importance of fighting costs in the context of intraspecific predation. From a theoretical perspective, our results support the three-individual encounter model developed by Garay et al. (2015). This model stresses the importance of the struggle between individual predators, which results in a low mortality rate. The ecological implications are clear: when growth and conversion rates are low enough, the balance of predator abundance is shown in the three-individual encounter model rather than in classical models. This can be explained by the results of the present study.

Likewise, from a practical point of view, the results found in this work could be important in explaining the efficacy of biological control of pests by augmentation (the periodic release of natural enemies), a predatory species in this case with a high level of cannibalism. Thus, on one hand, the results could imply a reduction in the effectiveness of the predator when biological control methods are carried out by inundative releases of a predator (at high rates) due to the combined effect of cannibalism and a reduction in the predatory rates among heterospecific species (a pest species in this case). On the other hand, the observed phenomenon can also reduce the effectiveness of biological control by inoculative releases (at low rates). These results corroborate the theoretical results found from the aforementioned model by Garay et al. (2015). All this leads us to take into account the role of cannibalism in biological pest control programmes and ensures that it will be assessed in field trials as well.
Acknowledgement: This work was funded by the Hungarian Scientific Research Fund OTKA (K81279).

\section{References}

Aleosfoor, M., N. Mortazavi and M. Poorkashkooli. 2014. Comparison cannibalistic behavior between two ladybirds, Coccinella septempunctata and Hippodamia variegata under laboratory experiments. Mun. Ent. Zool. 9: 645-650.

Braman, S.K. 2000. Damsel bugs (Nabidae). In: C.W. Shaefer and A.R. Panizzi (eds.), Heteroptera of Economic Importance. CRC Press. Boca Raton, FL., pp. 639-656

Bressendorff B.B. and S. Toff. 2011. Dome-shaped functional response induced by nutrient imbalance of the prey. Biol. Lett. 7: 517-520.

Cabello, T. 1988. Natural enemies of noctuid pests in alfalfa, corn, cotton and soybean crops in Southern Spain. J. Appl. Entomol. 108: 80-88.

Cabello, T., F. Bonfil, J.R. Gallego, F.J. Fernandez-Maldonado, M. Gamez and J. Garay. 2015. Can interactions between an omnivorous hemipteran and an egg parasitoid limit the level of biological control for the tomato pinworm? Environ. Entomol. 44: $12-26$.

Cabello, T., J.R. Gallego, F.J. Fernandez-Maldonado, M. Gamez, E. Vila, M. Pino and E. Hernandez-Suarez. 2012. Biological control strategies for the South American tomato moth (Lep.: Gelechiidae) in greenhouse tomatoes. J. Econ. Entomol. 105: 2085-2096.

Cabello, T., M. Gamez, A. Torres and J. Garay. 2011. Possible effects of inter-specific competition on the coexistence of two parasitoid species: Trichogramma brassicae and Chelonus oculator (Hym.: Trichogrammatidae, Braconidae). Community Ecol. 12: 78-88.

Cabello, T., M. Gamez and Z. Varga. 2007. An improvement of the Holling type III functional response in entomophagous species model. J. Biol. Syst. 15: 515-524.

Cabello, T., H. Rodriguez and P. Vargas. 1984. Development, longevity and fecundity of Sopodoptera littoralis (Lep.: Noctuidae) reared on eight artificial diets. J. Appl. Entomol. 97: 494-499.

Canon, 2014. Communication Software for the Camera EOS Utility, Version 2.14. Canon Inc.

Capinera, J.L. 2010. Insects and Wildlife. Wiley-Blackwell, Singapore.

Clercq, P. de, T.A. Coudron and E.W. Riddick. 2014. Production of heteropteran predators. In: J.A. Morales-Ramos, M.G. Rojas and D.I. Shapiro-Ilan (eds.), Mass Production of Beneficial Organisms: Invertebrates and Entomopathogens. Academic Press, Amsterdam. pp. 57-100.

Cock, M. 1978. The assessment of preference. J. Anim. Ecol. 47: 805-816.

Dixon, A.F.G. 2000. Insect Predator-Prey Dynamics: Ladybird Beetles and Biological Control. Cambridge University Press, Cambridge.

Dong, Q. and G.A. Polis. 1992. The dynamics of cannibalistic populations: a foraging perspective. In: M.A. Elgar, M.A. and B.J. Crespi (eds.), Cannibalism: Ecology and Evolution among Diverse Taxa. Oxford University Press, Oxford. pp. 13-37.

Elgar, M.A. and B.J. Crespi. 1992. Ecology and evolution of cannibalism. In: M. A. Elgar and B.J. Crespi (eds.), Cannibalism: Ecology and Evolution among Diverse Taxa. Oxford University Press, Oxford. pp. 1-12. 
Fagan, W.F. 1997. Omnivory as a stabilizing feature of natural communities. Am. Nat. 150: 554-567.

Fathipour Y. and A.A.F. Jafari. 2003. Functional response of predators Nabis capsiformis and Chrysoperla carnea to different densities of Creontiades pallidus nymphs. J. Agric. Sci. Nat. Resour. 10: $125-133$.

Fox, L.R. 1975. Cannibalism in natural populations. Annu. Rev. Ecol. Evol. S. 6: 87-106.

Garay, J. and F.T. Mori. 2010. When is the opportunism remunerative? Community Ecol. 11: 160-170.

Garay, J., Z. Varga, M. Gamez and T. Cabello. 2015. Functional response and population dynamics for fighting predator, based on activity distribution. J. Theor. Biol. 368: 74-82.

Hack, M.A. 1997. The energetic costs of fighting in the house cricket, Acheta domesticus L. Behav. Ecol. 8: 28-36.

Hagen, K.S., N.J. Mills, G. Gordh and J.A. McMurtry. 1999 Terrestrial arthropod predators of insect and mite pests. In: T.S. Bellows, T.W. Fisher, L.E. Caltagirone, D.L. Dahlsten, G. Gordh and C.B. Huffaker (eds.), Handbook of Biological Control: Principles and Applications of Biological Control. Academic Press, London. pp. 383-503.

Hamdi, F., J. Chadoeuf, B. Chermiti and O. Bonato. 2013. Evidence of cannibalism in Macrolophus pygmaeus, a natural enemy of whiteflies. J. Insect Behav. 26: 614-621.

Holling, C.S. 1959. The components of predation as revealed by a study of small-mammal predation of the European pine sawfly. Can. Entomol. 91: 293-320.

Holling, C.S. 1961. Principles of insect predation. Annu. Rev Entomol. 6: 163-182.

Hurd, L.E. 2008. Predation: The role of generalist predators in biodiversity and biological control. In: J.L. Capinera (ed.), Encyclopedia of Entomology. Springer, Dordrecht, NL. pp. 3038-3042.

IBM. 2012. IBM SPSS Statistics for Windows, Version 21.0. IBM Corp. Armonk, NY.

Jandel Scientific. 1994. Table Curve 2D User's Manual. Version 2.0. Jandel Scientific. San Rafael, CA.

Jeschke J.M., M. Kopp and R. Tollrian. 2004. Consumer-food systems: why type I functional responses are exclusive to filter feeders. Biol. Rev. 79: 337-349.

Joyner, K. and F. Gould. 1987. Conspecific tissues and secretions as sources of nutrition. In: F. Slansky and J.G. Rodriguez (eds.), Nutritional Ecology of Insects, Mites, Spiders, and Related Invertebrates. Wiley, NY. pp 697-719.

Juliano, S.A. 2001. Nonlinear curve fitting. Predation and functional response curves. In: S.M. Scheiner and J. Gurevitch (eds.), Design and Analysis of Ecological Experiments. Oxford University Press, Oxford. pp. 178-196.

Kishida, O., G.C. Trussell, K. Nishimura and T. Ohgushi. 2009. Inducible defenses in prey intensify predator cannibalism. Ecology 90: 3150-3158.

Latham, D.R. and N.J. Mills. 2009. Quantifying insect predation: a comparison of three methods for estimating daily per capita consumption of two aphidophagous predators. Environ. Entomol. 38: $1117-1125$.

Leon-Beck, M. and M. Coll. 2007. Plant and prey consumption cause a similar reductions in cannibalism by an omnivorous bug. J. Insect Behav. 20: 67-76.

Mangeaud, A. and M. Videla. 2005. En busca de la independencia perdida: la utilización de modelos lineales generalizados mixtos en pruebas de preferencia. Ecol. Austral 15: 199-206.
Manly, B.F.J., P. Miller and L. Cook. 1972. Analysis of a selective predation experiment. Am. Nat. 106: 719-736.

Mayntz, D., D. Raubenheimer, M. Salomon, S. Toft and S.J. Simpson. 2005. Nutrient-specific foraging in invertebrate predators. Science 307: 111-112.

Mills, N.J. 1982. Voracity, cannibalism and coccinellid predation Ann. Appl. Biol. 101: 144-148.

Motulsky, H. and A. Christopoulos. 2003. Fitting Models to Biological Data Using Linear and Nonlinear Regression: A Practical Guide to Curve Fitting. GraphPad Software, Inc., San Diego, CA.

Perkins, P.V. and T.F. Watson. 1972. Biology of Nabis alternatus (Hem.: Nabidae). Ann. Entomol. Soc. Am. 65: 54-57.

Pfennig, D.W., H.K. Reeve and P.W. Sherman. 1993. Kin recognition and cannibalism in spadefoot toad tadpoles. Anim. Behav. 46: 87-94.

Polis, G.A. 1981. The evolution and dynamics of intraspecific predation. Annu. Rev. Ecol. Evol. S., 12: 225-251.

Propp, G.D. 1982. Functional response of Nabis americoferus to two of its prey, Spodoptera exigua and Lygus hesperus. Environ. Entomol. 11: 670-674.

Puchkov, A.V. 1980. Particulars of the biology of predacious Nabis spp. Zashch. Rast. 8: 44.

Ramirez, C.C., E. Fuentes-Contreras, L.C. Rodríguez and H.M Niemeyer. 2000. Pseudoreplication and its frequency in olfactometric laboratory studies. J. Chem. Ecol. 26: 1423-1431.

Ricard, I. 2008. Statistical Methods for Insect Choice Experiments PhD Dissertation. École Polytechnique Fédérale de Lausanne, Lausanne, $\mathrm{CH}$

Riechert, S.E. 1988. The energetic costs of fighting. Integr. Comp. Biol. 28: 877-884

Rudolf, H.W. 2008. Impact of cannibalism on predator-prey dynamics: size-structured interactions and apparent mutualism. Ecology 89: 1650-1660.

Santana, A.F., A.C. Roselino, F.A. Cappelari and F.S. Zucoloto 2012. Cannibalism in insects. In: A.R. Panizzi and J.R.P. Parra (eds.), Insect Bioecology and Nutrition for Integrated Pest Management. CRC Press and Taylor and Francis Group, Boca Raton, FL. pp. 177-194.

Schenk, D., L.F. Bersier and S. Bacher. 2005. An experimental test of the nature of predation: neither prey- nor ratio-dependent. $J$. Anim. Ecol. 74: 86-91.

Schmitz, O.J. 2007. Predator diversity and trophic interactions Ecology 88: 2415-2426.

Schneider, C.A., W.S. Rasband and K.W. Eliceiri. 2012. NIH Image to ImageJ: 25 years of image analysis. Nat. Methods 9: 671-675.

Sherratt, T. and I. Harvey. 1993. Frequency-dependent food selection by arthropods: a review. Biol. J. Linn. Soc. 48: 167-186.

Siddique, A.B. and R.B. Chapman. 1987. Functional response of Pacific damsel bug, Nabis kinbergii (Hem.: Nabidae). Entomophaga 32: 303-309.

Statgraphics. 2010. Statgraphics Centurion XVI User Manual. StatPoint Technologies, Inc., Warrenton, VA.

Stasek, D.J. 2009. Population Responses of a Generalist Insect Predator and its Prey to Patch Characteristics in Forage Crops. PhD Dissertation. Faculty of Miami University, FL.

Toft, S. and D.H. Wise. 1999. Behavioral and ecophysiological responses of a generalist predator to single- and mixed-species diets of dfferent quality. Oecologia 119: 198-207. 
Ulusoy, M.R. and S. Ulgenturk. 2003. The natural enemies of whiteflies (Hem.: Aleyrodidae) in southern Anatolia. Zool. Middle East 28: 119-124.

Vila, E. and T. Cabello. 2014. Biosystems engineering applied to greenhouse pest control. In: I. Torres and R. Guevara (eds.), Biosystems Engineering: Biofactories for Food Production in the XXI Century. Springer, Berlin. pp. 99-128.

Wade M.R., M.P. Zalucki and B.A. Franzmann. 2005. Influence of observer presence on Pacific damsel bug behavior: who is watching whom? J. Insect Behav. 18: 651-667.
Wagner, J.D. and D.H. Wise. 1996. Cannibalism regulates densities of young wolf spiders: evidence from field and laboratory experiments. Ecology 77: 639-652.

Weber, M.J., J.M. Dettmers, D.H. Wahl and S.J. Czesny. 2010. Effects of predator-prey interactions and benthic habitat complexity on selectivity of a foraging generalist. T. Am. Fish. Soc. 139: 1004-1013.

Received March 20, 2017

Revised May 2, 2017

Accepted May 11, 2017 